\title{
NICARAGUA EN EL CONTEXTO DE LA COOPERACIÓN OFICIAL EXTERNA: CONSTRUCTIVISMO Y SANCIONES POLIITICAS
}

Edwin N. Montes

\section{Resumen}

Este trabajo constituye un pequeño aporte al estudio y análisis de los dilemas que por más de treinta años han enmarcado a la Cooperación Oficial Externa en Nicaragua. Su condición socioeconómica -principalmente la pobreza y demás factores asociados a ésta- ha permitido ubicar a Nicaragua dentro de los lineamientos de la Ayuda Oficial (AOD) diseñados por los cooperantes miembros del Comité de Asistencia al Desarrollo (CAD-OCDE).

Desde los años 80's el Estado nicaragüense ha sido receptor de fondos de cooperación siendo sus principales objetivos el combate a la pobreza y la promoción del crecimiento económico y el desarrollo social. No obstante, a la fecha, mucho de los cooperantes tradicionales, con amplia trayectoria en el territorio nacional han tomado la decisión de retirarse del país y otros han efectuado recortes en sus presupuestos de ayuda, pero se observa que los objetivos de mejoramiento de las condiciones de vida y reducción de la pobreza aún siguen en la palestra del debate.

Se pretende dar respuestas a preguntas que contienen la esencia de esta investigación: ¿Cuál ha sido el papel de la cooperación internacional en el combate a la pobreza en Nicaragua? ¿Las políticas del Estado nicaragüense junto con los mecanismos de desembolsos del donante han sido eficaces en la promoción del desarrollo social de Nicaragua?

Palabras Clave: Asistencia Oficial al Desarrollo/ Nicaragua/ Condicionalidad política/ pobreza/ eficacia

\section{Abstract}

This work is a small contribution to the study and analysis of the dilemmas that for more than thirty years have framed the Official External Cooperation in Nicaragua. Socioeconomic status mainly poverty and related factors - has allowed locating Nicaragua within the guidelines of Official Development Assistance (ODA), designed by engaging members of the Development Co-operation Directorate. (DCD-DAC))

Since 80's, Nicaraguan state has been receiving cooperation funds directed to poverty reduction and promotion of economic growth and social development. Nevertheless, to date, many traditional donors with extensive experience within the national territory, have taken the decision to leave the country, others have done cuts to Aids budgets. On the other hand objectives of improving living conditions and reducing poverty still in debate.

This research intended to provide answers to questions: What has been the role of international cooperation in the fight against poverty in Nicaragua?

Have policies of the Nicaraguan state along with donor's mechanisms disbursements been effective in promoting social development of Nicaragua?

Keywords: Official Development Assistence/ Nicaragua/ political conditionality/poverty/ efficacy 


\section{Introducción}

$\mathrm{N}$ icaragua es un país que se ha caracterizado por su dependencia frente a la cooperación internacional, figurando como uno de los países de la región centroamericana que más Ayuda Oficial al Desarrollo (AOD) per cápita recibe.

A manera de documentación, entre 19791989, los flujos de cooperación internacional recibidos por el Estado nicaragüense osciló en el orden de los US\$7,914.3 millones de dólares, de donde el $57.0 \%$ era proveniente de los países de la Europa Oriental, expaíses socialistas (Vargas; 2000: 129); de 1990 y 2006 osciló en unos US\$ 450.0 y US\$ 600.0 millones de dólares anuales; ${ }^{1}$ y entre 2007-2010 la cooperación oficial proporcionada a Nicaragua fue de un total de US\$1,615.6 millones de dólares (Asamblea Nacional; 2011).

Durante los últimos años la Ayuda Oficial al Desarrollo (AOD) ha sido cuestionada debido a los escasos resultados obtenidos en la reducción a la pobreza en los países en vías de desarrollo receptores de ésta. De igual forma por la poca claridad y transparencia en los fines de la misma. (Better Aid; 2010).

A pesar que el país ha experimentado un ritmo de crecimiento observable en estos últimos años, los avances en la lucha contra la pobreza y la reducción de la brecha social aún representa un reto para el gobierno actual.
De igual manera, Nicaragua está experimentando un proceso de transición en el marco de la cooperación oficial externa, dejando de ser un país receptor de ayuda vía donaciones (ayuda no reembolsable $)^{2}$ para pasar a la modalidad de créditos o préstamos; tomando en cuenta también que muchos de los cooperantes están perdiendo su presencia física en el territorio nacional.

Valdría la pena preguntarse: ¿han logrado los flujos de ayuda internacional el impacto esperado en el desarrollo del país? ¿Las políticas del gobierno nicaragüense y los mecanismos de desembolso de ayuda del donante realmente han sido eficaces en la lucha contra la pobreza?

El presente trabajo tiene la finalidad de contribuir en el análisis del papel y los efectos que la cooperación (Ayuda Oficial al Desarrollo) ha desempeñado en el combate a la pobreza en Nicaragua, haciendo énfasis en la perspectiva de la condicionalidad política a partir del mecanismo de gestión de la cooperación internacional.

\section{Definición y principales órganos gestores de la AOD}

La Ayuda o Asistencia Oficial al Desarrollo $(A O D)^{3}$ forma parte integral de lo que se denomina Cooperación Internacional; es decir, constituye sólo un segmento de esta última. Hay quienes confunden y asemejan ambos conceptos sin establecer diferencia alguna entre la generalidad presente en el término Cooperación Internacional y la especificidad de $A O D$.

1 Cifra obtenida del Plan para la Gestión Estratégica de la Ayuda Oficial al Desarrollo 2011-2013, del Gobierno de Nicaragua.

2 Para 2011 las donaciones oficiales externas para Nicaragua fueron de US\$246.7 millones de dólares, en cambio, para 2012 se redujeron a US\$227.3 millones de dólares. Informe Banco Central 2012.

3 La definición "Oficial" data desde 1973 en que será brindada por el Comité de Asistencia al Desarrollo de la OCDE, y alude, en primer término, al hecho de ser cooperación gestada por medio de Agencias Oficiales de Cooperación creadas por las administraciones centrales de los donantes; y segundo, por el principio rector o regulador en que ésta se sustenta. 
Para una mayor comprensión del presente estudio se hace imprescindible un breve recorrido por la Historia de este fenómeno y la incorporación de la definición de Ayuda Oficial al Desarrollo, entendida como la transferencia de recursos (sean estos económicos, materiales, técnicos o humanos) de origen públicos, distribuido por Agencias Oficiales, ${ }^{4}$ gobiernos regionales y locales, entregada directamente $\mathrm{o}$ a través de Agencias Multilaterales (PNUD, UNICEF, FAO, BID, ect.) por parte de los Estados donantes, con el fin de fomentar el desarrollo en las zonas más empobrecidas del planeta.

El Sistema Internacional de Ayuda al Desarrollo (SIAD) encuentra su esencia histórica en 1947 con la implementación del famoso plan de ayuda para la reconstrucción de Europa, devastada por la Segunda Guerra Mundial, conocido como Plan Marshall. Este sistema fue desarrollado por la Administración Central de Estados Unidos. A partir de esta estructura Europa se constituye en el primer continente receptor de ayuda.

Para 1960, cuando el Plan Marshall había cumplido en gran medida sus objetivos, los países beneficiarios de dicho programa, invitaron a Estados Unidos y Canadá a crear una organización que asumiera las funciones de coordinadora de las políticas de cooperación entre los países occidentales, surgiendo de esta manera la Organización para la Cooperación y el Desarrollo Económico (OCDE).

La principal instancia de la $O C D E$ encargada de las políticas de cooperación con los países en vías de desarrollo, es el
Comité de Ayuda al Desarrollo (CAD$O C D E)$. Desde este momento el $C A D$ figura como el ente y líder estabilizador del Sistema Internacional de Ayuda.

Los países donantes que integran son: Alemania, Australia, Austria, Bélgica, Canadá, Corea del Sur, Dinamarca, España, Estados Unidos, Finlandia, Francia, Grecia, Irlanda, Italia, Japón, Luxemburgo, Noruega, Suiza, Nueva Zelanda, Países Bajos, Portugal, Reino Unido y Suecia.

\section{Breve contexto histórico de la AOD en Nicaragua}

Nicaragua comienza a ser foco receptor de este tipo de ayuda a partir de los años 1980s, tras el triunfo de la Revolución Popular Sandinista. La situación de emergencia del país llevó al nuevo gobierno a buscar ayuda en el exterior. La cooperación de los países nórdicos no se hizo esperar, del mismo modo que la cooperación petrolera de México (1982-1984) y de España, Italia, Canadá y de la antigua Unión Soviética. (Contreras; 1991).

A solicitud del Gobierno de Nicaragua y con el objetivo de la reconstrucción nacional, se efectuaron a nivel internacional, distintas conferencias con la finalidad de recaudar fondos. Tal es el caso de la reunión del Sistema Económico para América Latina y el Caribe (SELA) del 30 de julio al 2 de agosto de 1979, donde se constituye el Comité de Acción para la Reconstrucción de Nicaragua; En septiembre de 1979 la CEPAL aprobó una resolución económica en la que invitaba a países de la ONU a cooperar con Nicaragua y a facilitar el acceso a fondos comerciales similares a los

4 El término Agencias Oficiales hace referencia a los organismos gestores de la cooperación en un territorio determinado y que han sido creados por las Administraciones Centrales de sus respectivos Estados de origen para cumplir dicha función. Ejemplos de estas Agencias son: USAID (Estados Unidos), NORAD (Noruega), DANIDA (Dinamarca), AECID (España), GIZ (Alemania), JICA (Japón), COSUDE (Suiza), etc. 
concedidos a países con menor desarrollo relativo; Para junio de 1989 se realizó en Estocolmo (Suecia) una conferencia donde se logró recaudar fondos de cooperación la cual fue considera como exitosa.

En 1983 cuando la crisis política que afectara al país durante toda la década, empieza a sentirse con fuerza, en especial por sanciones de organismos internacionales, la ayuda comienza a disminuir (condicionalidad negativa). Uno de los actores externos beligerantes en la crisis nicaragüense, Estados Unidos establece un embargo comercial, utilizando su poder de influencia en las decisiones de Organismos Financieros Internacionales, a pesar que Nicaragua era miembro del General Agreement on Tariffs and Trade $(G A A T)^{5}$. Esta potencia del Norte, bloquea préstamos por la suma aproximada de US\$ 390.9 millones aprobados por el Banco Interamericano de Desarrollo (BID) y el Banco Internacional de Reconstrucción y Fomento (BIRF). Además suspendería programas bilaterales en marcha entre entre ambos países (Nicaragua y EE. $\mathrm{UU})$, por un monto de US\$32 millones. (Contreras, 1991: 73).

Otra característica de la cooperación recibida por Nicaragua durante los 80 s fue que estuvo influenciada por el conflicto ideológico Este-Oeste. Muchas de las ONGDs presentes durante ese período provenían del bloque socialista (una condicionalidad política-ideológica cuyo objetivo era tratar de ganar aliados a nivel internacional).

Los daños materiales producto de la guerra fueron estimados por la CEPAL en US\$
481 millones (Nolff, 1982: 36). Debido a la situación de guerra en que se encontraba sumergida Nicaragua, los gastos en defensa de la soberanía, el endeudamiento externo se profundizaría. Toda la ayuda recibida en esa época era destinada principalmente al avituallamiento de las tropas que luchaban en las fronteras del país. (ADESH, 2007: 03)

La cooperación llevó a Nicaragua a un endeudamiento externo nunca antes visto. En su mayoría eran líneas de crédito con el bloque soviético, el cual crecía a un promedio anual de $17.2 \%$, registrando un saldo anual de 8, 253.8 millones a finales de 1989. (Ibid: 61).

Para la década de 1990, con el gobierno de Violeta Barrios de Chamorro y en un nuevo escenario político, Estados Unidos levantó el embargo comercial. Durante el primer año de esta nueva administración nacional, se recibieron US\$ 600 millones de dólares en concepto de donaciones externas. Esta ayuda estaba condicionada a la cancelación inmediata de la deuda ${ }^{6}$ y a los acuerdos con la Agencia de Fomento al Desarrollo (IDA), el Banco Mundial y el Fondo Monetario Internacional.

En el marco del nuevo contexto, el gobierno nicaragüense empieza a contraer compromisos y estructurar planes de renegociación de la deuda externa. La condición para que Nicaragua llevara a efecto planes de renegociación de deuda con cualquier acreedor privado, era necesario cumplir con una serie de requisitos macroeconómicos (mejor conocido como Programas de Ajustes Estructurales) estipulados por organismos

5 En 1961 Estados Unidos emitió la Ley de Cooperación Internacional por media de la cual se prohibía destinar ayuda a todo país comunista, incluido Cuba, y a cualquier otro país que prestara ayuda a Cuba. Amnistía Internacional. "El Embargo Estadounidense contra Cuba, su impacto en los derechos económicos y sociales". Madrid. 2009.

6 A finales de 1990 la deuda externa de Nicaragua era de US\$10.715 millones equivalente a 6,8 veces el valor del PIB y 27,4 veces el valor de las exportaciones de bienes y servicios. Para 1996 el saldo de la deuda sufrió una reducción sustancial quedando en US\$ 6.094,3 millones gracias a condonaciones generosas como las otorgadas por la República Federativa de Rusia y México. 
financieros internacionales como el FMI $y$ $B M^{7}$.

Durante la década de los 90s la economía nicaragüense estuvo sometida al estricto control de los Programas de Ajuste Estructurales (ESAF). El primer acuerdo del gobierno con el FMI es iniciado el 25 de mayo de 1994, a la vez, se negocia un crédito para la recuperación económica con el Banco Mundial. Sin embargo, el incumplimiento del gobierno de las metas establecidas para reducir el déficit público, conllevó a la suspensión de los desembolsos y créditos acordados con el FMI; y el BM.

Para 1998, durante la administración del Presidente Arnoldo Alemán, se firma el segundo ESAF. Este programa era una condición impuesta por la comunidad donante a Nicaragua, de no brindar ayuda si no se firmaba otro acuerdo, además del cumplimiento de las medidas pendientes del primer acuerdo. (Rodríguez, 2006: 4142). Por medio de este segundo programa, Nicaragua pudo ingresar a la Iniciativa de Países en Vías de Desarrollo Altamente Endeudados (HIPC), de acuerdo con los criterios estipulados por las IFIS ${ }^{8}$. La Iniciativa HIPC establecía la condonación del $90 \%$ de la deuda que el gobierno había contraído con el Club de París hasta 1989 (US\$ 281 millones).

Para el 2004 Rusia condonó a Nicaragua la deuda bilateral contraída por el gobierno sandinista durante la década de los 80 s
(1979-1990) la cual ascendía a casi 400 millones de dólares. Durante esta década, la desaparecida Unión Soviética vendió armas, equipos pesados, alimentos y petróleo al país (AFP; Julio 2004). Por otra parte, en julio de 2006, el Banco Mundial condonó US\$ 694 millones en el marco de la iniciativa del Alivio de la Deuda Multilateral (IADM) del grupo de los 8 (G8). (PNUD, mayo 2007: 5-6)

Así mismo, para el 2011, Libia condona 195.8 millones de dólares (62\% de la deuda total). Deuda contraída por Nicaragua, igualmente en la década de los 80s (Cárdenas; Febrero 2011). También hay que destacar la condonación de deuda que el Gobierno de Irán hizo efectiva en 2012 la cual superaba los 160 millones de dólares.

\section{Nicaragua en el Marco de la Agenda Internacional al Desarrollo}

A partir de la Cumbre del Milenio en el 2000, y la promulgación de los Objetivos de Desarrollo del Milenio (ODMs) -como metas a conseguir por los países en vías de desarrollo con apoyo de los cooperantes-, seguida por la Cumbre sobre Financiación deMonterrey (2002), se plantea la necesidad de promover una ayuda internacional de mayor calidad y cantidad. Se reafirma nuevamente uno de los compromisos adquiridos en los años 70 's, donde se insta a los países desarrollados a destinar el $0.7 \%$ de su Renta Nacional Bruta (PIB) como $A O D$ para los países en vías desarrollo. ${ }^{9}$

7 Los programas de ajuste estructural tratan entre otras cosas de: desregular el mercado de trabajo, reducir el tamaño del Estado y sus competencias, liberalizar el comercio interno y externo y desregularlo. Tanto el I y II Programa ESAF contraído por Nicaragua tenían una duración de tres años.

8 Dentro de estos criterios que permitieron ingresar a Nicaragua dentro de la Iniciativa HIPC cabe destacar principalmente los siguientes: el saldo de la deuda en 1997 representaba tres veces el PIB; el servicio de la deuda representaba el $56 \%$ de las exportaciones de bienes y servicios; y el $85 \%$ de los ingresos ordinarios del gobierno central. De Rodríguez Alas, Tomás Ernesto. "Ajuste Estructural y Desarrollo Rural en Nicaragua". Cuadernos de Investigación No. 16. Instituto de Investigación y Desarrollo Nitlapán, UCA, Managua. pp. 44.2006.

9 Hasta la fecha son pocos los países miembros del CAD quienes cumplen la meta establecida del 0.7\%, e incluso la crisis económica que afecta a Europa ha impulsado a muchos países a realizar recortes en sus presupuestos de AOD. En 2012 los países que cumplen dicha meta son: Luxemburgo (1\%), Suecia (0.99\%), Noruega (0.93\%), Dinamarca (0.84\%), Holanda (0.71\%). Consultar Anexo No. 1: "Ayuda al Desarrollo". 
Como resultado de estas dos Cumbres se realiza el I Foro de Alto Nivel en Roma, 2003, y el II Foro de Alto Nivel en Paris, 2005, sobre armonización y alineamiento de la cooperación internacional. De estos eventos surge la Declaración de París sobre la Efectividad de la Ayuda $(D P),{ }^{10}$ que propiciará el diseño de 12 indicadores que servirán de mecanismo de monitoreo y evaluación para una mayor efectividad de la $A O D$.

La docena de indicadores de eficacia de la AOD presentes en la Declaración de París (DP) constituyen desde ese momento, un instrumento de seguimiento y evaluación, buscando hacer más eficaces los compromisos de los adherentes al convenio, en relación a la obtención de mayores y mejores resultados en el desarrollo y la lucha contra la pobreza en el mundo.

En el 2006 se realizó a nivel de 34 países socios (incluido Nicaragua), la primera medición de los indicadores (12) para establecer la línea de base (año 2005). Los resultados obtenidos, evidenciaron un conjunto de problemas tales como: falta de coordinación entre donantes y receptores la cual seguía siendo alta; persistencia de ayuda atada; divergencias entre las políticas de la fuente y la aplicación en el campo; limitada apropiación local; poco avance en la gestión por resultados. (Fernández Andrade; 2009: 81).

La última encuesta de medición de la Declaración de París (DP) para Nicaragua se realizó en el 2008 con datos del 2007. De acuerdo con esta encuesta, Nicaragua se encontraba en una posición moderada en el cumplimiento de los indicadores de los 5 principios que constituyen la $D P$.

Con posterioridad, a principios de septiembre de 2008, en Accra, Ghana, se efectúa el III Foro de Alto Nivel relacionada con la Declaración de París, cuyo resultado fue el "Programa de Acción Accra". El objetivo era aclarar y profundizar la aplicación de la DP y evaluar los avances obtenidos de dicha Declaración.

El Gobierno de la República de Nicaragua, tras los resultados de evaluación obtenidos en la Encuesta 2008 y en correspondencia con lo establecido en la Declaración de París y el Programa de Acción Accra, presentó en noviembre del 2009, con motivo de la reunión del Grupo de Trabajo sobre la Efectividad de la Ayuda, en París, un Conjunto de Acciones para el Aumento de la Efectividad de la Ayuda Oficial al Desarrollo 2009-2011.

Parte de estas políticas, lo constituye la definición de un sistema de diálogo articulado (No formal, voluntario $\mathrm{y}$ local), entre donantes e instituciones gubernamentales basadas en relaciones de respeto al proceso de conducción nacional relativas a la ejecución de la cooperación internacional.

De igual forma, a nivel gubernamental se formularon programas sectoriales con el propósito de seguir la línea de cumplimiento de los ODM: Programa Nacional de Electrificación Sostenible y Energía Renovable (PNESER), Educación (Batalla por 6to.Grado, campañas de alfabetización), Modelo de Salud Familiar y Comunitario (MOSAFC), Producción

10 Este Instrumento internacional constituye un proyecto ambicioso de reforma al sistema de gestión, implementación, seguimiento y evaluación de la AOD. Gira en torno a cinco principios fundamentales (Apropiación, Alineación, Armonización, Gestión Orientada a Resultados y Mutua Responsabilidad) que concentran en esencia los 12 indicadores de medición de la efectividad de la ayuda y que vinculan tanto a donantes como a países socios, con el fin de establecer un marco de referencia que contribuya a la eficiencia de la misma. 
(Bono Productivo/ Usura Cero), e infraestructura, por destacar algunos.

El eje articulador de estas acciones lo constituye el Plan Nacional de Desarrollo Humano (PNDH) el cual establece las prioridades de desarrollo apuntalando el combate a la pobreza extrema, estabilidad macroeconómica-financiera, bienestar social y equidad social (seguridad alimentaria, educación de calidad para todas y todos, restitución del derecho humano a la salud, restitución de derechos de niñas y niños a una niñez digna y felizPrograma Amor-, acceso a agua potable y saneamiento), perspectiva productiva, perspectiva del medio ambiente, cambio climático y desastres naturales (medio ambiente, prevención, atención y mitigación ante desastres naturales), desarrollo de la Costa Caribe y acciones para la buena gestión pública. ${ }^{11}$

En este mismo sentido, del 29 de noviembre al $1^{\circ}$ de diciembre de 2011, en Busan, Corea del Sur, se llevó a cabo el IV Foro de Alto Nivel sobre Eficacia de la Ayuda (4to. FAN), donde se analizó el avance y cumplimiento de los acuerdos contraídos en Accra, Ghana (2008). Al respecto es pertinente destacar los grandes esfuerzos que realizado por el Estado de Nicaragua, diseñando acciones destinadas a la armonización y alineación de las políticas nacionales con las estrategias trazadas por los donantes.

Nicaragua es considerada un país ejemplar por ser der pionero en la iniciativa de llevar a cabo un proceso de coordinación de los recursos externos, anterior a la Declaración de París. En consecuencia, entre 2002-2006, se establecieron mesas sectoriales de trabajo (Salud, Educación,
Infraestructura, Gobernabilidad, Producción y Competitividad), espacios de coordinación de donantes, grupos multi-actores del proceso nacional de alineamiento y armonización; espacios de discusión a nivel político y foros públicos anuales de seguimiento del proceso de coordinación de la cooperación; siendo a la vez, un país que ha logrado avanzar hacia nuevas modalidades de cooperación: Fondo Común, Apoyo Presupuestario y Enfoques Sectoriales Amplios (SWAPs).

Hay un elemento clave señalado por la DP, relacionado a la cooperación internacional, aún consolidar en Nicaragua, el cual constituye a la vez en un factor propicio para alcanzar un nivel optimo de desarrollo y de combate a la pobreza, es el liderazgo (ownership) mejor conocido como la apropiación, que el gobierno debe de ejercer en la gestión de los recursos de $A O D$ : "para que la ayuda sea eficaz, los donantes deben respetar las prioridades y los procesos de desarrollo del país socio antes que sus propias políticas y prácticas de desarrollo". ${ }^{12}$

El Viceministro de Relaciones Exteriores de Nicaragua y Secretario de Cooperación Externa Valdrack Jaentschke (2011), refiriéndose al tema anterior dijo: "Este proceso es un proceso extremadamente impuesto, un proceso extremadamente planteado por el Norte, lo que hemos tenido que tratar de hacer es detenerlo, tratar de ordenar las cosas y tratar de apropiarnos de algunos elementos".

En esta medida, hay que tener presente que para una buena efectividad de la ayuda en el desarrollo de los países socios, además de la cantidad (que los donantes cumplan con la meta de destinar el $0.7 \%$ de su PIB en

11 Plan para la Gestión Estratégica de la Ayuda oficial al Desarrollo 2010-2013, octubre 2010, p. 4.

12 OCDE. "Cooperación para el Desarrollo: Informe 2010". Pág.3. 
concepto de $A O D$ ) y la calidad de la misma, es indispensable que los gobiernos de estos países receptores tomen el liderazgo en la gestión de los recursos que se les otorgan.

De esta forma, el Gobierno de Nicaragua ha diseñado un "Plan para la Gestión Estratégica de la Ayuda Oficial al Desarrollo 2010-2013", cuyo objetivo principal es lograr el liderazgo en la gestión de los desembolsos. Para ello, se enfatiza en la creación de un "Espacio Global de Diálogo" entre Instituciones Globalistas (Secretaría de la Presidencia, Ministerio de Hacienda y Crédito Público y Ministerio de Relaciones Exteriores), Jefes de Misiones Diplomáticas y Representantes de Organizaciones Internacionales, donde surjan acuerdos comunes entre los cooperantes y el gobierno referente a las prioridades nacionales de desarrollo y de los nuevos modelos de cooperación. ${ }^{13}$

Es así como el actual gobierno trabaja en la separación del modelo de desarrollo implementado durante los gobiernos neoliberales, denominado "Donor Driven" donde los planes nacionales de desarrollo giraban en torno a las políticas de los donantes. Lo que se busca es dar paso a un modelo denominado "Country Driven", donde las políticas de cooperación deban realizarse por medio de la conducción nacional.

Sin embargo, pese a los esfuerzos del gobierno sandinista en pro de una mayor coordinación y conducción nacional en la gestión de los recursos de cooperación, los donantes aún se muestran reticentes a brindar los espacios necesarios en el proceso de apropiación de la Ayuda.

¿A qué se debe que los donantes no permitan una verdadera apropiación en Nicaragua? La OCDE da una serie de explicaciones basadas en experiencias y celos de liderazgos quizás:

Por temor a la corrupción o por falta de capacidad. Por ejemplo, a muchos cooperantes les parece demasiado arriesgado permitir que un país en desarrollo tenga pleno poder de decisión sobre lo que hace con el dinero recibido en ayuda. Sin embargo, hay que sopesar los riesgos que se perciben en el uso de los sistemas nacionales, y los beneficios, que a menudo no se comprenden o no se comunican lo suficiente. Una razón es que los beneficios son institucionales, de largo plazo y difusos. ${ }^{14}$

Por otro lado, es importante destacar que ante los efectos de la crisis económica en la Comunidad Europea, el cambio de gobierno y las supuestas anomalías registradas con los resultados de las elecciones municipales 2008 , los donantes han intentado mantener en alguna medida el modelo implementado durante los gobiernos neoliberales ("Donor Driven". Continúan concentrando sus esfuerzos de destinar la ayuda por la vía del instrumento proyecto, eliminando modelos de cooperación más eficaces como lo son el Apoyo Presupuestario ${ }^{15}$ y los Enfoques Programáticos.

Reconociendo el papel trascendental de la cooperación, y de su larga presencia en el

13 Plan para la Gestión Estratégica de la Ayuda Oficial al Desarrollo 2010-2013, Pág. 5

14 OCDE. "Informe de Cooperación 2010". Pág. 3

15 Un estudio realizado de forma independiente en el 2005 sobre el apoyo presupuestario general en Burkina, Faso, Malawi, Mozambique, Ruanda, Uganda, Vietnam y Nicaragua, encargado por la OCDE, demostró que estos países beneficiarios con este instrumento de cooperación, habían favorecido a las personas en extrema pobreza a través de la ampliación de los servicios sociales. . IDD and Associates. 'Evaluation of General Budget Support: Synthesis Report', OCDE/CAD, Birmingham, Reino Unido. 2006. 
territorio nacional, la pregunta que muchos se han hecho es ipor qué el impacto de la ayuda externa en el desarrollo de Nicaragua y la reducción de la pobreza no se ha hecho sentir de la forma esperada?

En principio, debe recordarse que en los años 1980s la AOD que ingresó a Nicaragua era para alivio. En otras palabras, "significó un paliativo, un remedio para las consecuencias de la guerra y no un agente de desarrollo" ${ }^{16}$ Será a partir de los 90s que tomará una nueva línea de acción representada en la lucha contra la pobreza. No obstante, los resultados obtenidos por medio de esta línea de acción no fueron positivos, principalmente por los niveles de corrupción y mala gestión pública que generaron. ${ }^{17}$

Durante la gestión liberal, los recursos de Cooperación Externa estuvieron concentrados principalmente hacia el objetivo del crecimiento económico. Los dirigentes políticos al igual que la mayoría de los cooperantes, reforzaron la idea de que únicamente mediante el crecimiento económico era posible mejorar las condiciones de vida de la población y reducir la pobreza. Las palabras del excanciller de Nicaragua Norman Caldera son más que elocuentes: Debemos de poner mayor énfasis en el crecimiento, o canalizar los fondos limitados más hacia la infraestructura que hacia el desarrollo social para alcanzar el momentun de crecimiento, especialmente en países Hipcs, como Nicaragua. ${ }^{18}$
Es bueno resaltar que Nicaragua ha crecido en términos económicos, pero los avances en la generación de empleo y lucha contra la pobreza aún requieren de mayores esfuerzos. Se ha propiciado una especie de "crecimiento empobrecedor", parafraseando a economistas especialista en temas latinoamericanos, quienes así han catalogados a países como Nicaragua, que se encuentran dentro de la categoría de países de Renta Media:

[...] Latinoamérica y el sur de Asia han experimentado largos períodos de crecimiento económico que coexisten con incrementos significativos del empleo informal. En algunos países en desarrollola proporción de trabajadores informales puede representar más del $90 \%$ si se incluye a la agricultura en la estimación. La gran correlación entre informalidad, pobreza y vulnerabilidad es una manifestación de la paradoja del "crecimiento empobrecedor". Como mínimo los donantes deben focalizarse en apoyar procesos que incrementen las capacidades de las personas pobres para aprovechar efectivamente el crecimiento económico. (Intermón Oxfam, 2010:31).

\section{Retiro de Cooperantes miembros del CAD-OCDE y el elemento condicionante en Nicaragua.}

Desde décadas atrás, la cooperación internacional ha desempeñado un papel trascendentalenla promoción deldesarrollo y combate a la pobreza en Nicaragua.

16 Embajada de Japón en cooperación con el Ministerio de Relaciones Exteriores de Nicaragua. "Seminario sobre la Cooperación Económica: Crecimiento o Reducción de la Pobreza". Centro Medioambiental del Parque Japonés - nicaragüense, Managua, 8 de Junio de 2006. pág. 31

17 Durante la Administración de Arnoldo Alemán, en el 2000, muchos de los países cooperantes, entre ellos los países nórdicos (Suecia, Finlandia, Noruega y Dinamarca) decidieron suspender su ayuda a Nicaragua en virtud de problemas con la fiscalización en el uso de los bienes del Estado y de garantías en el manejo transparente de los fondos de cooperación por parte de la Contraloría de Nicaragua.

18 Embajada de Japón en cooperación con el Ministerio de Relaciones Exteriores de Nicaragua. "Seminario sobre la Cooperación Económica: Crecimiento o Reducción de la Pobreza". Centro Medioambiental del Parque Japonés - Nicaragüense, Managua, 8 de Junio de 2006. pág. 23 
También ha llegado a considerarse parte del problema estructural de país. Un $85 \%$ de la ayuda es "atada", es decir, el donante es quien determina la oferta, los mecanismos de desembolso y ejecución (PNUD, 2007:10), restándole por ende al gobierno toda posibilidad de establecer sus prioridades y políticas nacionales de desarrollo.

En tiempo recientes, países cooperantes como Noruega, Dinamarca y Holanda -siguiendo los pasos de Inglaterra (2009) y Suecia (2010)- decidieron retirarse del país. Algunos atribuyen la decisión de retirar la cooperación a la situación política del país, sobre todo esgrimiendo el tema las elecciones municipales de 2008 y las elecciones presidenciales del 2011; Otros señalamientos apuntan a la crisis económica internacional que afecta a Europa y una tercera a nuevos mecanismos de cooperación, priorizando regiones con mayores necesidades que la de países de América Central, como es el caso de Africa.

En junio de 2009, países, organismos miembros del Grupo de Apoyo Presupuestario (GAP) y demás entes de cooperación, se reunieron para constituir una Mesa de Donantes ${ }^{19}$ donde se analizó la situación vivida en el país tras los resultados de las elecciones municipales de 2008. Producto de esta reunión se hizo una recomendación pública indicando que para reanudar la Ayuda en el país era necesario "perfeccionar el Sistema Electoral" destacando a la vez que "un ambiente positivo para la cooperación para el desarrollo, requiere de una muestra clara de compromiso de los principios democráticosfundamentales [...] el derecho a las elecciones libres, transparentes $y$ justas por parte de las autoridades públicas y los dirigentes políticos"20 (Agencia EFE; 19 noviembre 2008).

Siguiendo la anterior tónica, el ex embajador de Estados Unidos en Nicaragua Robert Callahan, enfatizaba: "seguimos pidiéndole al gobierno que encuentre una solución [...] a las irregularidades que existieron con respecto a las elecciones municipales, para sí recuperar la confianza en su sistema electoral" (Agencia AFP, Junio 2009)

Producto de la "indiferencia" del gobierno nicaragüense a las recomendaciones dadas, el gobierno de los Estados Unidos retiró la Cuenta Reto del Milenio ${ }^{21}$ la cual tenía proyectos en el occidente del país (León y Chinandega). Ante esa medida el gobierno venezolano compensó esa "sanción", aprobando una ayuda para continuar con algunos proyectos en esa región, esta vez controlados por el gobierno. (EFE, Mayo 2011).

En relación al tema de la cooperación y las exigencias, el ex embajador de Noruega en Nicaragua, Tom Tyrihjell señalaría en una entrevista brindada a El Nuevo Diario:

...en la mesa de cooperantes hemos contribuido a abrir espacios de diálogo, hemos logrado avances y espero que esa relación un poco más balanceada y no solamente crítica, rinda frutos. Democracia y transparencia han sido temas recurrentes. En la Mesa Global

19 La Mesa de Donantes estaba conformada por las embajadas de Alemania, Luxemburgo, España, Dinamarca, Noruega, Finlandia, Japón, Holanda, Suecia, Francia, Canadá, Estados Unidos, La Comisión Europea, Islandia, Italia, Austria y la Agencia Suiza para el Desarrollo y la Cooperación (COSUDE).

20 Consultar Sección Anexos Gráfico No. 5 "Recurso Totales Dirigidos al Sector Público por Año y Sector Económico (Millones de Dólares).

21 El retiro de la Cuenta Reto del Milenio al Occidente de Nicaragua significó un monto de 62 millones de dólares de un total de 175 millones de dólares "no reembolsables" para un período de cinco años destinados a proyectos de desarrollo sostenible y de reducción de la pobreza en las provincias de León y Chinandega. 
(de donantes) nosotros enfatizamos en estos estándares y en las expectativas de la comunidad donante. (Córdoba, octubre 2010).

Hay que destacar también el comunicado de prensa publicado en el sitio web de la Embajada de los Países Bajos con sede en Managua, donde se llega a afirmar que: "mientras el gobierno de Nicaragua cumpla con los 'principios fundamentales', establecidos en la JFA, se seguirá (en principio) dando el apoyo presupuestario". ${ }^{22}$ Así mismo, respecto a la percepción de gobernabilidad que tiene este país europeo hacia Nicaragua se destaca lo siguiente:

En Nicaragua se puede observar una especie de péndulo que se mueve entre tendencias hacia la modernización e institucionalización del Estado y movimientos contrarios que quieren revivir el autoritarismo y el clientelismo político. El país tiene un marco legal bastante completo, pero en algunas ocasiones falta la voluntad política para cumplir las leyes y los políticos aprovechan el Estado y el gobierno para sus propios fines y ventajas (“Estado Botín"). ${ }^{23}$

Algunos expertos justifican acciones como las anteriormente descritas, tal es el caso de Burnside y Dollar, cuyos estudios demuestran que las instituciones políticas son fundamentales para incentivar el crecimiento económico y el desarrollo social. Estos autores señalan que la ayuda o cooperación sólo tiene efectos positivos en el crecimiento económico de aquellos países receptores que practican buenas políticas (Burnside y Dollar; 2000: 847-868).
El ejemplo de Suecia (ASDI) ha sido catalogado por muchos como uno de "los donantes más generosos y respetuosos Los países en desarrollo lo ven como un donante responsable y dedicado. Esta reputación ha permitido a Suecia jugar un papel que va más allá de su "ayuda al desarrollo" (Koumi, 2006: 1). Pero también, es uno de los muchos donantes defensores de principios democráticos, siendo uno de los integrantes de la Mesa de Donantes conformada tras los resultados de las elecciones municipales en 2008, y que suspendieron temporalmente la ayuda retirándose de manera definitiva pocos años después.

En abril de 2009, en el contexto de la crisis económica internacional y el eventual descenso en el volumen de la ayuda, el PNUD presentó un análisis en el que planteaba la necesidad absoluta de inversión en gobernanza democrática porque,

...el trabajar con menos recursos públicos para ayudar a más personas necesitadas significa que los gobiernos tienen que ser mejores a la hora de prestar servicios y asegurar igualdad e inclusión en los ámbitos económico, social y político (criterio de eficacia). (PNUD, 2009:1).

Si en ocasiones la condicionalidad en el ámbito político no se logra visualizar fácilmente es por la forma discrecional en que ésta se practica, y fundamentalmente, por la retórica y las múltiples excusas diplomáticas utilizadas por losembajadores $\mathrm{y}$ altos funcionarios representantes de las agencias de cooperación acreditadas en el país:

22 Consultar página web, Embajada del Reino de los Países Bajos, sección Cooperación al Desarrollo, Apoyo Presupuestario, Gobernabilidad en: nicaragua.nlembajada.org. Nota: las iniciales JFA hace referencia a Acuerdo Financiero Común. [consultado 24 de mayo de 2013]

23 Ibíd. Sección Cooperación al Desarrollo, Gobernabilidad. En: nicaragua.nlembajada.org 
Teórica y empíricamente los economistas ven la asignación de la ayuda exterior, como una redistribución de los recursos de los países desarrollados a países en desarrollo, motivados principalmente por el deseo altruista de contribuir en la reducción de la pobreza, pero durante los últimos diez años se han generado grandes debates y se han considerado las motivaciones del donante como estratégicas y no como si pudieran conducir al desarrollo económico del país receptor (Balla y Yannitell; 2008).

La condicionalidad -ya sea en su faceta positiva o negativa- ha sido un instrumento utilizado por los gobiernos de los donantes para crear en los receptores las condiciones necesarias que propicien el crecimiento y el desarrollo en beneficio mutuo, donante y receptor, y no sólo de una sola vía receptor a como algunos piensan. No existe ningún donante que imponga condiciones a un país sin que estas medidas sean compatibles con los intereses del primero. (Prado Lallande; 2006: 466)

En relación a este tipo de planteamientos cabe destacar el juego del "mixed-motive games", donde no sólo se manifiesta una dependencia mutua entre donante y receptor, sino también la asociación. Aunque no debe de descartarse el conflicto producido de la bipolaridad de realidades culturales, económicas diferentes (desarrollo y subdesarrollo; Norte y Sur). (Steinberg, 2008:156)
De igual manera, cabe destacar los argumentos de retiro de la ayuda a causa de los efectos de la crisis económica internacional. Los principales recortes de $A O D$ en Nicaragua durante el 2010 provino de la Eurozona debido en parte a los problemas de deuda soberana que está afectando a la mayor parte de esos países, creando inestabilidad en esta zona económica y especulaciones en los sistemas financieros internacionales. El historiador nicaragüense Aldo Díaz Lacayo señala que los cooperantes europeos "buscan cómo racionalizar la ayuda a través de un elemento político" (Díaz; Julio 2011).

Otro elemento destacable señalado como parte de las causas de "re direccionar" los fondos de Ayuda al Desarrollo, ha sido el factor seguridad internacional surgido a partir de los atentados del 11 de septiembre de 2001. Esto ha repercutido en la las políticas de prioridades de desarrollo de mecanismo de salvaguarda de intereses nacionales de los grandes donantes. ${ }^{24}$

Nicaragua posee una característica macroeconómica particular, lo cual constituye otro factor determinante en la fuga de cooperantes, y es el ser considerado como país de renta media baja. ${ }^{25}$ Posee un Producto Interno Bruto (PIB) per cápita de US\$ 1, 582 dólares. ${ }^{26}$ Desde esta perspectiva, los cooperantes justifican su retiro aduciendo que las razones históricas de su presencia, como el índice de pobreza, ha bajado a niveles que no justifican su

24 Es de notar que los principales países receptores de AOD en el mundo son Irak y Afganistán. CUNSULTAR Anexos cuadro No. 5, "Principales Receptores de AOD bruta del Conjunto de Países del CAD en 2008".

25 Para el 2003 el Banco Mundial brindó un informe en el que establecía una clasificación de países según el ingreso per cápita: Renta Alta, Renta Media y Renta Baja. En dicho informe se estipulaba que un país de Renta Media es aquel que posee un ingreso per cápita que oscila entre un rango mayor a \$US 745 y menor a los \$US 9.206. Nicaragua de acuerdo con las cifras 2010 del Banco Central posee un Producto Interno Per Cápitia de \$US 1,126.5 lo que lo cataloga como un país de Renta Media Baja.

26 Cifras Oficiales del Banco Central de Nicaragua correspondientes a septiembre 2012. 
presencia en el país. Por tanto, fijan sus prioridades en países que consideran con mayores desventajas que Nicaragua como pueden encontrarse algunos en África y Asia.

\section{La eficacia de la ayuda en Nicaragua}

El PNUD en su informe "Revisión de la Evidencia de Evaluación en la Efectividad de la Ayuda" (2001) establece diferencia entre dos tipos de eficacia:

a. Eficacia organizativa: Aprecia el logro del objetivo que se propuso la acción de desarrollo diseñada por el ejecutor/ donante. Básicamente se centra en el cumplimiento del objetivo trazado, en los resultados (outputs) del proyecto o programa, pero con independencia de la pertinencia o prioridad de los beneficiarios. Lo primario es la consecución del proyecto, independientemente de la situación obtenida con los beneficiarios.

b. Eficacia en el desarrollo: Centra su atención en el impacto de la ayuda, en el modus vivendis de las personas. Eso significa que se dirige hacia los cambios producidos en la población objetivo y su entorno (outcomes). Dentro de esta perspectiva se afirma que la ayuda es eficaz si brinda oportunidades a las personas y mejora sus condiciones de vida.

En este sentido, mientras la eficacia organizativa centra su evaluación a nivel micro (proyectos y programas considerados de manera aislada) la eficacia en el desarrollo enfoca su evaluación a nivel macro. Eso significa que además de evaluar el logro y cumplimiento del proyecto, también analiza el proceso de desarrollo del país y la población objetivo.
En el caso de Nicaragua se presenta una problemática relacionada a los programas y proyectos impulsados por las Agencias de Cooperación, principalmente, por la enorme cantidad de proyectos financiados y ejecutados en el país de manera aislada, sin plena coordinación entre los donantes. Cada uno de ellos emplea sus propios métodos y procedimientos, lo que resta liderazgo al gobierno en determinar sus propias prioridades de desarrollo. (Rouquayrol, 2007: 68)

Por otra parte, el tipo de eficacia que se aplica en Nicaragua con la ejecución de los programas y proyectos es la Eficacia Organizativa. En primer lugar, los donantes impulsan muchos proyectos de manera particular y dispersa. En segundo lugar, si se parte del criterio objetivo que no todos los proyectos logran cumplir los objetivos trazado, los resultados de cumplimiento del mismo no se evalúan conforme indicadores generales que evidencien mejoras en el nivel de desarrollo nacional, ¿qué quiere decir esto?, que el nivel micro no trasciende al macro de la eficacia en el desarrollo. Por último, en su mayoría los proyectos se hacen conforme el Plan Nacional de Desarrollo Humano.

\section{Conclusiones}

En síntesis, no es para sorprenderse o alarmarse si el Estado de Nicaragua deja de percibir fondos de cooperación vía donaciones, pues al contrario, revela un aspecto positivo en cuanto que expresa la conquista de la independencia que el país está adquiriendo respecto al sistema internacional de Asistencia al Desarrollo (SIAD). Es producto de su condición o momento económico por el que atraviesa actualmente el país.

De lo anterior, es necesario observar que Nicaragua, al dejar de percibir fondos 
de cooperación vía donaciones, pasa a una segunda modalidad dentro de los lineamientos de Cooperación Oficial Externa: el préstamo o crédito. Es aquí entonces donde la cooperación tradicional (proveniente de los países occidentales) poco a poco va cediendo espacio, abandonando viejas prácticas, para dar lugar a una nueva de tipo constructivista (No tradicional) propia de la denominada Cooperación Sur-Sur o Cooperación Alternativa (China, Rusia, Venezuela, India, México, Brasil, etc.), convirtiéndose ésta -como su palabra bien lo indica- en una opción o alternativa para Nicaragua.

De esta forma, la historia de la cooperación internacional en Nicaragua se constituye en la expresión de estos dos grandes enfoques: el constructivismo y las sanciones políticas (interés político).

Por último, aunque los objetivos de combate a la pobreza fijados por la cooperación no han logrado reflejarse muy significativamente a nivel macro del desarrollo de Nicaragua, se hace necesario resaltar que los avances de un país no depende directamente de los flujos de cooperación, sino de manera significativa de la capacidad productiva de ese país y el nivel de inversión extranjera directa. También se debe reconocer que un país que crece económicamente sin una política de distribución justa de la riqueza, sin un enfoque de mejora de las capacidades de los grupos más vulnerables y sin tener efectos significativos en la reducción de la pobreza, es imposible alcanzar niveles óptimos de desarrollo, sobre todo cuando se cuenta con un bono demográfico amplio como sucede en Nicaragua.

\section{Referencias Bibliográficas}

ACEVEDO Vogl, A. J. (2011). “Nicaragua: Contrataciones Públicas, Alineación y Armonización de la Cooperación Internacional". Fundación Carolina, Madrid.

ADESH. "República de Nicaragua". España, 4 de Junio de 2007. Consultado en: www.adesh.org

AFP. (agencia) (2009). “Cooperantes exigen Reformas al Sistema Electoral de Nicaragua". El Economista. 11 de junio de 2009. De: www. eleconomista.net

AFP (agencia) (2004). "Rusia nos perdona deuda". El Nuevo Diario. Consultado en: http://archivo.elnuevodiario. com.ni/2004/julio/27-julio-2004/ nacional/nacional-20040727-15.html

ASAMBLEA NACIONAL. (2011). “Síntesis sobre las directrices internacionales para cooperación eficaz en el Siglo XXI". Managua.

BALLA, E. y Yannitell Reinhardt, G. (2008) "Giving and receiving foreign aid: does conflict count?". En: World Development. Vol. 36, No. 12 ; p. 2566-2585.

BENDAÑA, A. (2008) "Modelos de Cooperación Internacional en Centroamérica: perspectivas de los movimientos sociales". Managua: CEI.

BEETER AID. “Eficacia del Desarrollo en la Cooperación para el Desarrollo: Una Perspectiva desde los derechos". 2010. Consultado en: www.betteraid. org. 
BURNSIDE C. y D. Dollar.(1997) “Aid, Policies and Growth Policy". Research. "Workingpaper, $\mathrm{n}^{\mathrm{o}}$ 1777, The World Bank.

CÁRDENAS Cruz, F. "Libia Condona Deuda a Nicaragua". México, Pulso Político Online, 15 de Febrero de 2011. Consultado en: portal.pulsopolitico. com.mx

CONTRERAS, F., et. alt. (1991). “Entre la Agresión y la CooperaciónLa Economía Nicaragüense y la Cooperación Externa en el Período 1979-1989". INICAE. Managua.

Declaración de París sobre la Eficacia de la Ayuda al Desarrollo, II Foro de Alto Nivel sobre Eficacia de la Ayuda al Desarrollo, 28 Febrero-2 Marzo de 2005, París, Francia.

DÍAZ Lacayo, A. Director Academia Diplomática "José de Marcoleta". Ministerio de Relaciones Exteriores de la República de Nicaragua (MINREX); Politólogo e Historiador; y Asesor Presidencial. [Entrevista]. Managua, 27 de julio 2011.

Agencia EFE, Terra Noticia Terra Actualidad.. (2008) "Paises Cooperantes piden Transparencia y Paz en el Conflicto Electoral en Nicaragua". 19 Noviembre. http:// noticias.terra.es

EMBAJADA DEL JAPÓN en cooperación con el Ministerio de Relaciones Exteriores de Nicaragua. (2006) "Seminario sobre la Cooperación Económica: Crecimiento o Reducción de la Pobreza". Centro Medioambiental del Parque Japonés - Nicaragüense, Managua.

FERNÁNDEZ Andrade, R. et. al. (2009)"Mito y Realidad de la Ayuda
Externa América Latina al 2009/ Una evaluación independiente de la cooperación internacional al desarrollo". México: ALOP. México.

GÓMEZ Galán, M. et. al.(2001) “La Cooperación al Desarrollo en un Mundo de Cambio/ Perspectivas sobre Nuevos Ámbitos de Intervención". Madrid: CIDEAL.

GÓMEZ Gil, C. Gómez - Olivé, D. Tarafa, G. "30 Años de Créditos FAD. " Observatorio de la Deuda en la Globalización. Editorial Icaria, Barcelona, pág. 158-160.

GÓMEZ Lacayo, M. \& Benavente Gómez, C. A. (2007) "Efectividad de la Cooperación y la Declaración de París:: Su Implementación en los Sectores de Educación y Gobernabilidad y el Impacto en el Financiamiento y Participación de las Organizaciones de la Sociedad Civil en Nicaragua". Un Informe por Alliance 2015. Managua: INGES.

HERNÁNDEZ， M. H. (2008) “Nuevos Sistemas Sectoriales en el Marco del Proceso de Alineamiento y Armonización de la Cooperación Internacional." España: Fundación Carolina CeALCI..

INTERMÓN OXFAM. “La Realidad de la Ayuda 2004-2005, Junto al Análisis cuantitativo y Cualitativo de la AOD Española". Estudios 13.

INTERMÓN OXFAM.(2011) “La Realidad de la Ayuda 2010. Una evaluación independiente de la ayuda y las políticas de desarrollo en tiempos de crisis". Informe.

JAENTSCHKE, V. (Viceministro de Relaciones Exteriores de Nicaragua y Secretario de Cooperación Externa). 
"Posiciones de América Latina 5: Nicaragua (Video)". Consultado el 15 de Agosto de 2011, en: http://foroaod.org/2008/09/04/ posiciones-de-america-latina-5nicaragua-video.

KEOHANE, R. y Nye, J. (1988) “Poder e Interdependencia. La Política Mundial en Transición". Buenos Aires: Gel.

Koumi, H. (2006). "La Cooperación para el Desarrollo: El Caso de Suecia - un País Donante".

NOLFF, Max. (1982) “La Vía Crucis de la Revolución Sandinista". Nueva Sociedad No. 63, NoviembreDiciembre, pp. 33-46.

PNUD, (2009). “La Gobernanza Democrática y el PNUD". Inforápida, PNUD. Abril

PNUD. (2007). “Evaluación de los Resultados de Desarrollo Nicaragua/ Evaluación de la Contribución del PNUD".Mayo

PRADO Lallande, Juan P. (2006) "La condicionalidad Política de la Cooperación al Desarrollo: Las sanciones a la Ayuda Internacional". Madrid: UCM.

PRADO Lallande, J. P.(2010) "La Condicionalidad de la Ayuda y el Enfoque de los Derechos Humanos: Propuestas Prácticas para la Cooperación Española". Fundación Madrid: Carolina CeALCI.
PRADO Lallande, J.; y Ochoa Bilbao, L. (2009) “El Sistema de Cooperación Internacional para el Desarrollo: frente a la securitización y la crisis económica global". Revista de Relaciones Internacionales de la UNAM, núm. 105, septiembre diciembre, pp. 37-61.

Programa de Acción Accra, III Foro de Alto Nivel sobre Eficacia de la Ayuda al Desarrollo, 2-4 de septiembre de 2008, Accra, Ghana.

RODRÍGUEZ Alas, T. E. (2006) "Ajuste Estructural y Desarrollo Rural en Nicaragua". Cuadernos de Investigación No. 16. Instituto de Investigación y Desarrollo Nitlapán, UCA, Managua. pp. 44.

ROUQUAYROL Guillemette, L.\& Herrero Villa, S.(2007). "Guía sobre la Cooperación Unión EuropeaAmérica Latina 2007". Proyecto Financiado por la Unión Europea. Francia: Ceficale.

SANTANDER Campos, G. (2010) "Violencia, Seguridad y Desarrollo en Centroamérica: El Papel de los Donantes". Madrid: CEIPAZ. Agosto.

STEINBRG, F. (2008).Cooperación y Conflicto en las relaciones económicas internacionales. Revista Española de Ciencias Políticas (Núm. 18). Madrid.

VARGAS, O-René. (2000). “Círculos del Infierno: corrupción, dinero y poder". Foro Democrático-CEREN, Nicaragua. 


\section{ANEXO No.1}

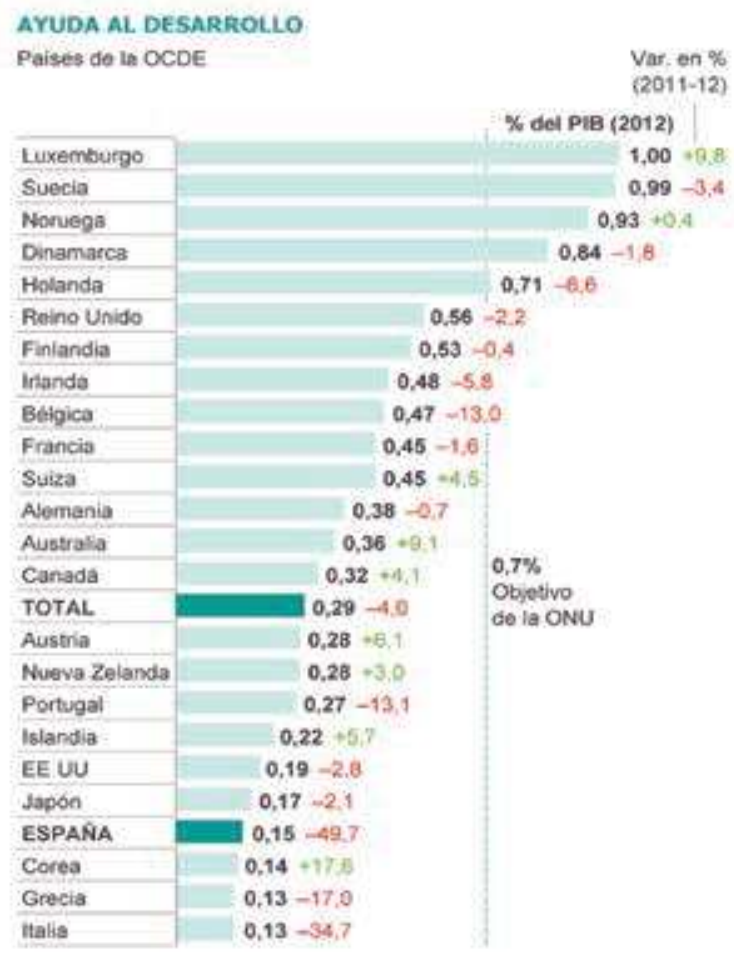

ANEXO No. 2

Princlpales receptores de AOD bruta del conjunto de paises del CAD en 2008

Milones de dobares
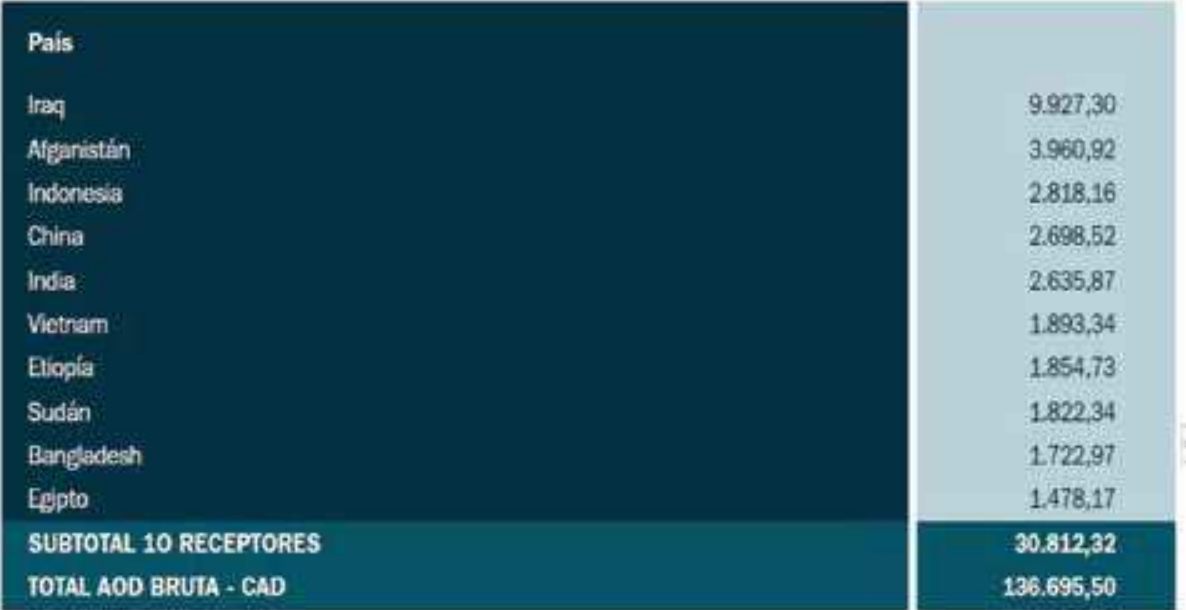

Fuente: Intermón Oxfam 2010, con datos del CAD-OCDE. 